Int. J. Electrochem. Sci., 16 (2021) Article ID: 21066

International Journal of

ELECTROCHEMICAL

SCIENCE

www.electrochemsci.org

\title{
Electrochemical Fabrication of a GO-NiO/AISI 316L Electrode and Its Evaluation for Glucose Detection
}

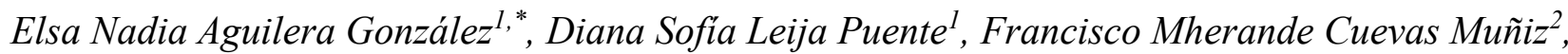 \\ Sofia Estrada Flores ${ }^{1}$, Antonia Martínez-Luévanos ${ }^{1}$ \\ ${ }^{1}$ Departamento de Materiales Cerámicos Avanzados y Energía, Facultad de Ciencias Químicas, \\ Universidad Autónoma de Coahuila, Saltillo, 25280 Coahuila, México, \\ ${ }^{2}$ Centro de Investigación y Desarrollo Tecnológico en Electroquímica, S.C. Parque Tecnológico \\ Querétaro Sanfandila, Pedro Escobedo, 76703 Querétaro, Mexico. \\ *E-mail: elsaaguilera@uadec.edu.mx
}

doi: $10.20964 / 2021.06 .03$

Received: 26 January 2021 / Accepted: 11 March 2021 / Published: 30 April 2021

This paper describes the fabrication of a GO-NiO/AISI 316L electrode and its subsequent evaluation for enhanced glucose detection. The GO-NiO/AISI $316 \mathrm{~L}$ electrode was fabricated in situ by the electrodeposition of a GO-NiO nanocomposite generated by cyclic voltammetry (CV) on an AISI 316L stainless steel substrate, with a subsequent thermal treatment at $400{ }^{\circ} \mathrm{C}$. The obtained electrode was characterized by scanning electron microscopy (SEM) and Fourier transform infrared (FTIR) spectroscopy. The effectiveness of the electrode to detect glucose was evaluated by both cyclic voltammetry and chronoamperometry (CA). SEM and FTIR results showed that GO-NiO nanocomposite was realized on the surface of the stainless steel substrate confirming the successful fabrication of the GO-NiO/AISI 316L electrode. Electrochemical experiments showed that the electrode catalyzed the electrochemical oxidation of glucose in an alkaline medium. Voltammetric results suggested that the glucose oxidation rate was controlled by glucose diffusion on the electrode surface. The GO-NiO/AISI 316L electrode could detect glucose in an alkaline medium in a linear range of 0.01 $\mathrm{mM}$ to $0.7 \mathrm{mM}$ with a response time of less than $5 \mathrm{~s}$, a detection limit of $0.05 \mathrm{mM}$ and a sensitivity of $744.68 \mu \mathrm{A} \mathrm{mM}^{-1} \mathrm{~cm}^{-2}$.

Keywords: Electrosynthesis; nanocomposite; nickel oxide; graphene oxide; glucose detection

\section{$\underline{\text { FULL TEXT }}$}

(C) 2021 The Authors. Published by ESG (www.electrochemsci.org). This article is an open access article distributed under the terms and conditions of the Creative Commons Attribution license (http://creativecommons.org/licenses/by/4.0/). 